\title{
Regional climate model simulations as input for hydrological applications: evaluation of uncertainties
}

\author{
S. Kotlarski ${ }^{1}$, A. Block ${ }^{2}$, U. Böhm ${ }^{3}$, D. Jacob ${ }^{1}$, K. Keuler ${ }^{2}$, R. Knoche ${ }^{4}$, D. Rechid ${ }^{1}$, and A. Walter ${ }^{5}$ \\ ${ }^{1}$ Max-Planck-Institut für Meteorologie, Hamburg (MPI), Germany \\ ${ }^{2}$ Brandenburgische Technische Universität, Cottbus (BTU), Germany \\ ${ }^{3}$ Potsdam Institut für Klimafolgenforschung, Potsdam (PIK), Germany \\ ${ }^{4}$ Forschungszentrum Karlsruhe, IMK-IFU Garmisch-Partenkirchen (IMK), Germany \\ ${ }^{5}$ Deutscher Wetterdienst, Offenbach (DWD), Germany
}

Received: 7 January 2005 - Revised: 1 August 2005 - Accepted: 1 September 2005 - Published: 16 December 2005

\begin{abstract}
The ERA15 Reanalysis (1979-1993) has been dynamically downscaled over Central Europe using 4 different regional climate models. The regional simulations were analysed with respect to $2 \mathrm{~m}$ temperature and total precipitation, the main input parameters for hydrological applications. Model results were validated against three reference data sets (ERA15, CRU, DWD) and uncertainty ranges were derived. For mean annual $2 \mathrm{~m}$ temperature over Germany, the simulation bias lies between $-1.1^{\circ} \mathrm{C}$ and $+0.9^{\circ} \mathrm{C}$ depending on the combination of model and reference data set. The bias of mean annual precipitation varies between -31 and $+108 \mathrm{~mm} /$ year. Differences between RCM results are of the same magnitude as differences between the reference data sets.
\end{abstract}

\section{Introduction}

The state of the atmosphere is an essential boundary condition for most hydrological applications. Near surface exchange processes such as evapotranspiration and sensible heat flux depend on the characteristics of the ambient air (Häckel, 1999). Furthermore, precipitation in form of rain and snow is the major source of water for runoff generation. Reliable information on local and regional meteorological parameters and their distribution in space and time is therefore strongly required by water balance and flood forecast models. In many cases, the necessary information can more or less accurately be derived from observational data sets. However, for large scale hydrological applications in data sparse regions and especially for climate change studies numerical climate simulations have to be utilised.

The corresponding climate models strongly differ with respect to their horizontal resolution, their degree of complexity and the incorporated physical parameterisation schemes.

Correspondence to: S. Kotlarski

(kotlarski@dkrz.de)
Global general circulation models (GCMs) for instance use grid spacings of more than $100 \mathrm{~km}$ which is often too coarse for catchment based hydrological investigations. Therefore, downscaling techniques have to be applied which generate horizontal distributions of climatic parameters based on the coarse GCM information but on a much finer scale (Wilby and Wigley, 1997). Besides statistical methods, regional climate models (RCMs) can be used for physically based dynamical downscaling. These models commonly use horizontal resolutions between 10 and $50 \mathrm{~km}$ and are able to dissolve important regional scale processes such as orographic lifting of air masses in complex terrain and the associated formation of clouds and precipitation. At their lateral boundaries, RCMs are either forced by GCM output or by global reanalyses. The simulated climate parameters (e.g. precipitation, near surface air temperature, specific humidity etc.) can subsequently be used as input for hydrological models (offline coupling).

It is important to notice that the information generated by RCMs is inevitably subject to uncertainties which propagate through the hydrological scheme and eventually influence model results. Uncertainties in regional climate simulations are potentially caused by a multitude of factors, the most important of which are

- missing or inadequate parameterisation of important subgrid scale processes (e.g. convection)

- shortcomings of numerical methods used

- choice of horizontal and vertical resolution

- uncertainties in boundary forcing

- treatment of boundary forcing

- choice of regional model domain (size and position)

- nesting hierarchy

- internal model variability 


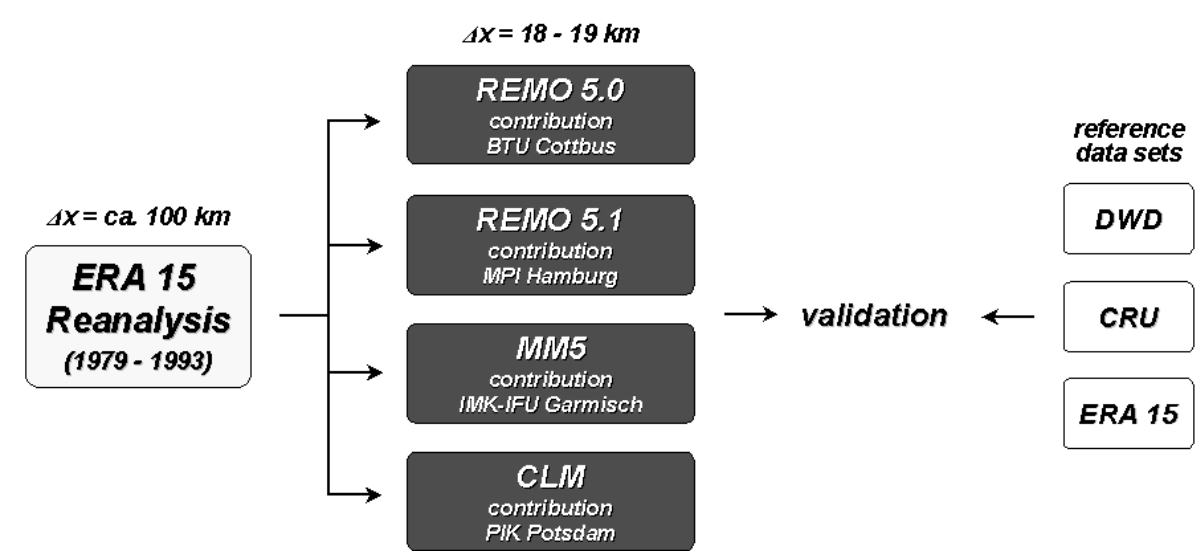

Fig. 1. Downscaling and validation concept in QUIRCS.

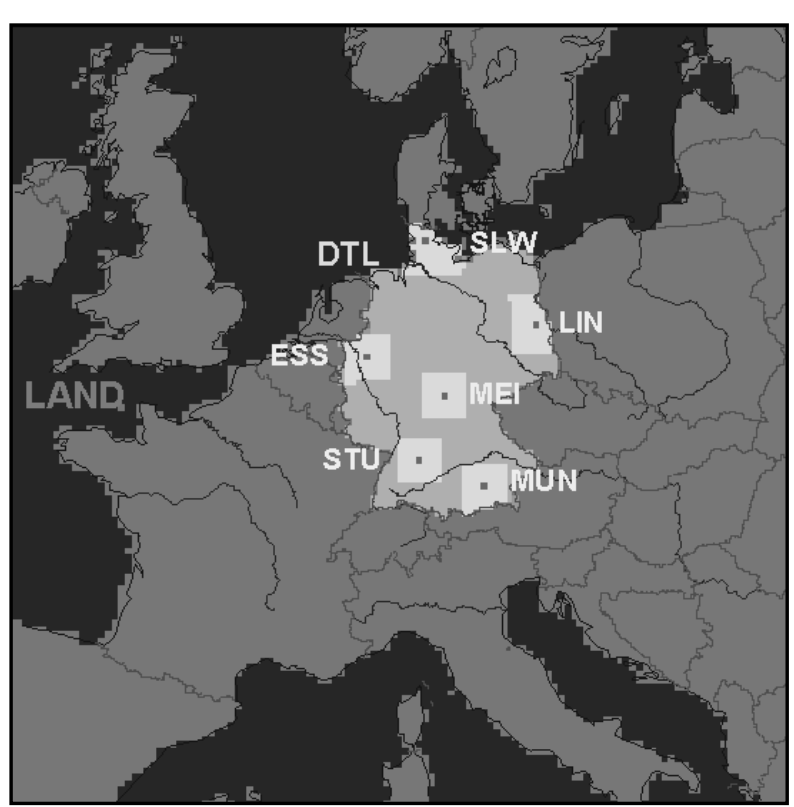

Fig. 2. Common reference domain and location of sub areas for model evaluation $(L A N D$ : land surface area in reference domain; DTL: Germany; SLW, ESS, LIN, MEI, STU, MUN: radiosonding sites)

- in climate change scenarios: choice of emission scenario (e.g. IPCC SRES)

One way to evaluate and to quantify the associated uncertainties for specific parameters are so called ensemble simulations (e.g. Murphy et al., 2004; Giorgi and Francisco, 2000). Here, a multitude of climate model runs is carried out under standardised conditions using either different models (multi model ensemble, e.g. PRUDENCE project: http://prudence.dmi.dk) or using the same model but different parameterisation schemes, boundary conditions, initialisations, resolutions etc. The whole set of simulations, i.e. different realisations of the "same" climate, is afterwards analysed statistically and uncertainty ranges are derived.
This contribution presents first results of the research project QUIRCS (Quantification of Uncertainties In Regional Climate and Climate Change Simulations) which is part of the German Climate Research Program (DEKLIM). Within QUIRCS, a multi model ensemble of present day regional climate simulations over Europe has been investigated and analysed with respect to a multitude of model parameters.

\section{Methodology}

In order to evaluate uncertainties of regional climate simulations caused by the choice of a specific model, the global ERA15 Reanalysis (1979-1993; Gibson et al., 1997) has been downscaled over Central Europe applying dynamical downscaling via several state-of-the-art RCMs (Fig. 1):

\section{- contribution BTU Cottbus:}

The hydrostatic regional climate model REMO 5.0 (Jacob and Podzun, 1997; Jacob, 2001) using a physical parameterization scheme adopted from the GCM ECHAM4 (Roeckner et al., 1996).

\section{- contribution MPI Hamburg:}

The hydrostatic regional climate model REMO 5.1. From version 5.0 to 5.1, a mean annual cycle of vegetation characteristics (albedo, leaf area index, vegetation ratio), freezing and melting of soil water and fractional land use have additionally been implemented (Semmler, 2002; Rechid and Jacob, $2005^{1}$ ).

- contribution IMK Garmisch-Partenkirchen:

A climate version of the non-hydrostatic mesoscale model MM5 (Grell et al., 2000).

\section{- contribution PIK Potsdam:}

The non-hydrostatic climate model CLM 2.0, an extended version of the operational forecast model of

\footnotetext{
${ }^{1}$ Rechid, D. and Jacob, D.: Influence of seasonally varying vegetation on the simulated climate in Europe, Meteorologische Zeitschrift, in review, 2005.
} 


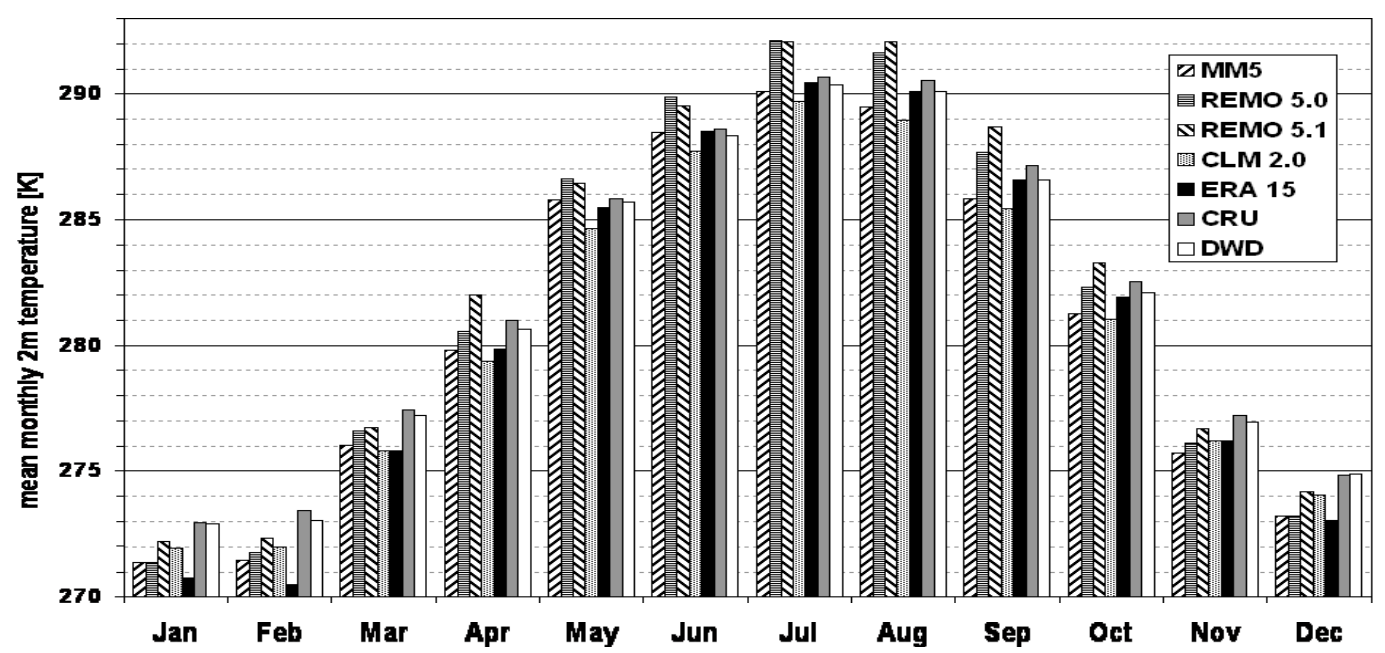

Fig. 3. Mean annual cycle of $2 \mathrm{~m}$ temperature over Germany (RCM simulations and reference data sets) [K].

the German Weather Service Lokalmodell (Doms and Schättler, 2002; Kücken and Hauffe, 2002).

Location and size of the model domain differs between RCMs, however all models cover Central Europe and use horizontal resolutions between 18 and $19 \mathrm{~km}$. For REMO 5.0, REMO 5.1 and CLM 2.020 vertical levels were used and 24 in case of MM5. As reference data for model validation, observation based data sets compiled by the German Weather Service (DWD, $1 \times 1 \mathrm{~km}^{2}$ grid) and the Climate Research Unit at University of East Anglia (CRU; New et al., 2002) as well as the ERA15 Reanalysis are used. Prior to intercomparison and validation of model results, all data sets (simulations and observations) were projected to a common $1 / 6^{\circ}$ reference grid using an interpolation method based on area weighting (the value for a specific reference grid cell equals the area-weighted arithmetic mean of all contributing grid cells of the original data grid). As the horizontal resolution of the evaluated data sets is similar (except for DWD and ERA15), this interpolation method is not expected to significantly modify the original spatial patterns. Subsequently, monthly mean values of $2 \mathrm{~m}$ temperature and precipitation were analysed for the whole of Germany (DTL) as well as for $6 \mathrm{sub}$ areas centered at radiosonding sites (Schleswig (SLW), Essen (ESS), Lindenberg (LIN), Meiningen (MEI), Stuttgart (STU) and Munich (MUN), Fig. 2). For each of these areas, the mean annual cycle of both investigated parameters has been calculated and uncertainty ranges were derived based on the found differences between the data sets. Additionally, the spatial patterns of annual mean values on the $1 / 6^{\circ}$ reference grid were analysed.

The present study focusses on air temperature and precipitation as they are the main input parameters for hydrological schemes and strongly determine near surface hydrological processes. Simulated runoff for example is expected to be markedly influenced by errors and uncertainties in temperature and precipitation input.

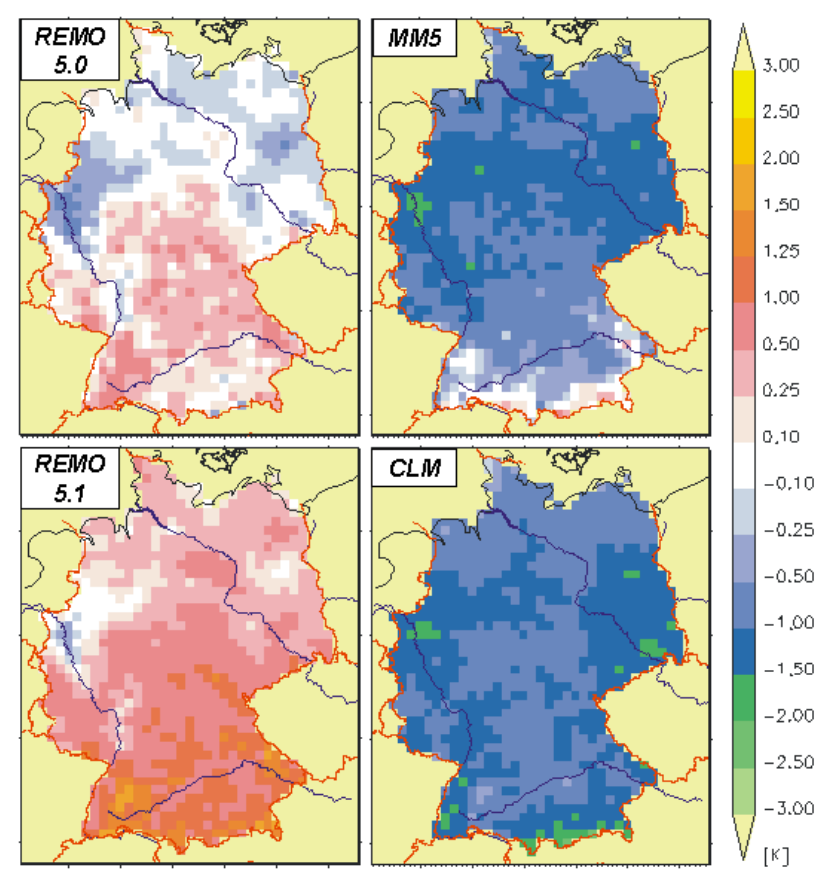

Fig. 4. Bias of mean annual $2 \mathrm{~m}$ temperature for all RCMs with respect to DWD reference data set $[\mathrm{K}]$.

\section{Results}

\section{$3.12 \mathrm{~m}$ Temperature}

Figure 3 shows the mean annual cycle of $2 \mathrm{~m}$ temperature over Germany as simulated by the RCMs and for the three reference data sets. The two observation based data sets (DWD and CRU) are in close agreement with each other (differences less than $0.5^{\circ} \mathrm{C}$ ). Minimum values of about $0^{\circ} \mathrm{C}$ $(273 \mathrm{~K})$ are reached in January and maximum temperatures of more than $17^{\circ} \mathrm{C}(290 \mathrm{~K})$ in July and August. The strong 


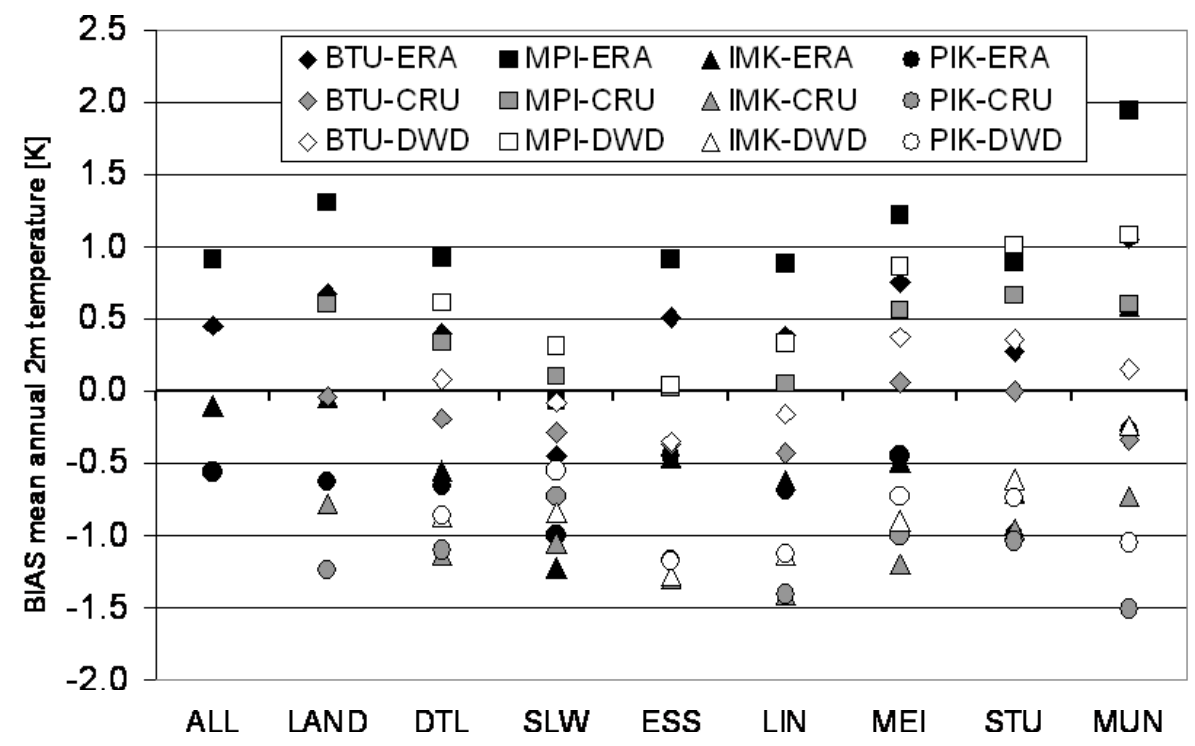

Fig. 5. Bias of mean annual $2 \mathrm{~m}$ temperature for different sub areas and for all combinations of RCM - reference data set [K].

accordance of two independently compiled observational data sets (though partly based on the same station records) strengthens our confidence in their accuracy. However, the ERA 15 Reanalysis, which is the result of 24-hour forecasts by a numerical weather prediction model based on assimilation of observation data at the time of initialisation, underestimates the observed $2 \mathrm{~m}$ temperature by about $2.5^{\circ} \mathrm{C}$ in wintertime. Similarly, all RCMs underestimate mean wintertime temperature by 0.5 to $1.5^{\circ} \mathrm{C}$. In case of the non-hydrostatic model MM5, this cold bias persists throughout the whole year. The two hydrostatic REMO versions show a quite distinct behaviour. From April to October, both models overestimate observed temperatures with a maximum bias of about $+1.5^{\circ} \mathrm{C}$ in July and August. The span between RCM results is largest during summertime (approx. $2^{\circ} \mathrm{C}$ ). In this period, the quality of representation of surface-air exchange processes and clouds plays a major role and consequently differences between simulations are largest.

For MM5 and CLM, the negative bias of annual mean temperature with respect to the DWD data set is homogeneously distributed over Germany (Fig. 4). Both models underestimate observed temperatures by 0.5 to $1.5^{\circ} \mathrm{C}$ in most areas. The two REMO simulations however exhibit larger regional differences in the temperature bias. REMO 5.0 for instance simulates too high temperatures in the southern half of Germany (bias up to $1^{\circ} \mathrm{C}$ ) while most areas in the northern half show a cold bias of the same magnitude. A similar spatial pattern can be observed for REMO 5.1 but on a systematically warmer level. Annual mean temperatures are overestimated in most parts of Germany except for some areas along the rivers Rhine and Ruhr and around Berlin. This warm bias is strongest in southern Germany (up to $+2^{\circ} \mathrm{C}$ ) and diminishes towards the North. It is mainly caused by too high simulated temperatures during the summer half of the year (see Fig. 3) which are possibly related to inaccuracies in the de- scription of vertical diffusion processes and to a pronounced drying phenomenon in late summer (see below).

In order to get a systematic overview of model performance and its spatial variability, the simulated mean annual temperature bias has been calculated for each RCM with respect to each reference data set for different sub areas as well as for the total area $(A L L)$ covered by the reference grid (Fig. 5). For the latter case ( $A L L$ ), only ERA 15 was available as reference since the CRU data set only covers the land surface and DWD data is only available for Germany. With respect to ERA 15, the simulated annual $2 \mathrm{~m}$ temperature (mean over the whole reference domain, $A L L$ ) is too high in case of both REMO versions and too low for MM5 and CLM with REMO 5.1 showing the strongest bias $\left(+0.9^{\circ} \mathrm{C}\right)$. Because all models are forced by the same prescribed sea surface temperature over the oceans, inter-model differences are even larger if only the land surface area (LAND) is being considered. However, if CRU is used as reference, biases are systematically shifted towards negative values which is caused by the difference between CRU temperature and ERA15 (with CRU temperatures being higher). Interestingly, the difference between the two reference data sets is of the same magnitude as variations between the single RCMs.

For the german area $(D T L)$, also the third reference data set (DWD) can be taken into account. With respect to all three references, MM5 and CLM underestimate mean annual temperature by more than $0.5^{\circ} \mathrm{C}$. On the opposite side, REMO 5.0 and 5.1 mostly exhibit too high temperatures except for the comparison of REMO 5.0 and CRU. Looking at the spatial means around six different radiosonding sites (SLW, ESS, $L I N, M E I, S T U, M U N$ ), the two REMO simulations are systematically located on the "warm" side while MM5 and CLM show a cold bias for each subarea. From North (Schleswig, $S L W$ ) to South (Munich, $M U N$ ), biases are generally shifted to more positive values (except for CLM). The southernmost 


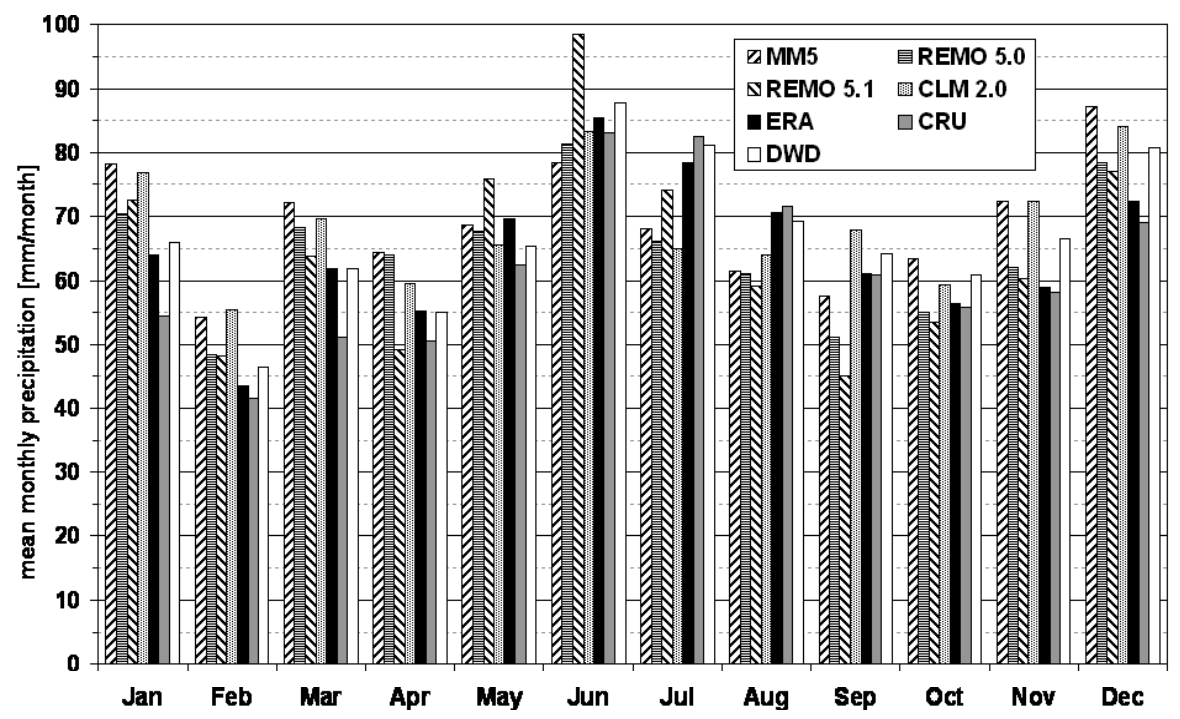

Fig. 6. Mean annual cycle of total precipitation over Germany (RCM simulations and reference data sets) [mm/month].

sub area Munich exhibits the largest ranges of temperature biases ( -1.5 to 1.9 depending on RCM and reference data set).

\subsection{Precipitation}

The mean annual cycles of total precipitation (rainfall + snowfall, Fig. 6) exhibit a stronger variability between the different data sets (simulations and references) than in case of $2 \mathrm{~m}$ temperature. In winter and spring, precipitation is mostly overestimated by the RCMs (up to $24 \mathrm{~mm} /$ month, $44 \%$ ) and the simulation results only differ by less than $10 \mathrm{~mm} / \mathrm{month}$ from each other. The simulated summertime precipitation however is too low in most cases (up to $-19 \mathrm{~mm} / \mathrm{month}$, $-30 \%)$ and differences between the single models are largest ( $>15 \mathrm{~mm} /$ month). It has to be noted, that both the DWD and the CRU data set have not been corrected for a systematic undercatch of precipitation due to wind drift, wetting of the gauge and evaporation losses. The corresponding measurement error is larger for snow than for rain (i.e. larger in wintertime than in summer) and can reach values of more than 35\% (Dyck and Peschke, 1995). This fact at least partly explains the higher amount of simulated wintertime precipitation compared to observations and the large differences between the reference data sets themselves. The general variation of precipitation throughout the year is similar for all simulations and reference data sets with peak values occuring in June and December and minima in February and September/October. During summertime, REMO 5.1 shows an anomalous performance characterised by an overestimation of precipitation in June and subsequently a strong decrease of mean monthly rainfall until September. This behaviour is probably connected to the annual cycle of vegetation characteristics implemented in this model (see above) which causes strong evaporation in early summer and consequently a rapid decline of soil water storage. In late summer,

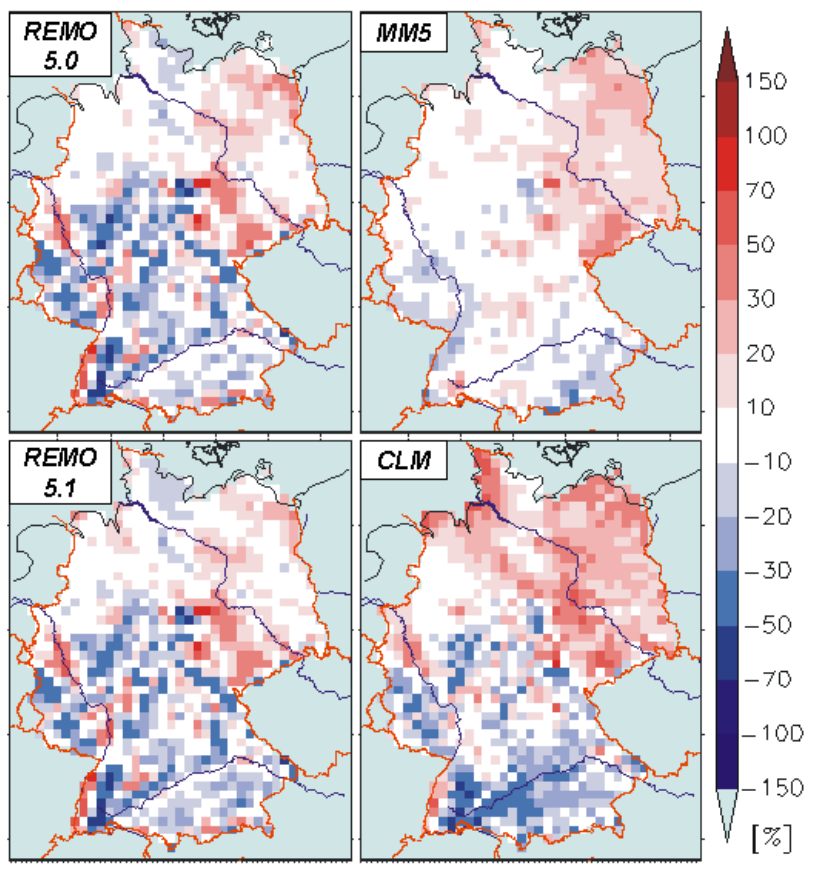

Fig. 7. Bias of mean annual total precipitation for all RCMs with respect to DWD reference data set [\%].

the dry soil prevents evaporation and therefore local water supply for the atmosphere resulting in a decrease of precipitation. The large model domain of the REMO 5.1 simulation extending far into North Africa might be a second reason for the simulated late summer drying.

The general spatial patterns of mean annual precipitation bias over Germany with respect to DWD data are similar for all RCMs (Fig. 7). Except for the eastern parts of the study area, MM5 shows relatively smooth deviation patterns. 
Table 1. Uncertainty ranges derived from multi model ensemble (area: Germany).

\begin{tabular}{lcc}
\hline parameter & bias & $95 \%$ percentile \\
\hline 2 m temperature & -1.1 to $0.9^{\circ} \mathrm{C}$ & 0.5 to $1.8^{\circ} \mathrm{C}$ \\
precipitation & -31 to $108 \mathrm{~mm} /$ year & 26 to $59 \%$ \\
\hline
\end{tabular}

Stronger spatial gradients of precipitation bias appear in case of the three other models (e.g. Upper Rhine Valley and adjacent Black Forest). Precipitation in the eastern part of Germany is overestimated by all models. The same is true for the Rhine valley except in the MM5 simulation. In eastern Germany, largest biases of up to $70 \%$ occur for CLM. The concerned areas are among the driest regions in Germany. Therefore, a relatively moderate overestimation of absolute precipitation sums results in a relatively large percentual bias. In most other parts of the study area (especially in southern Germany), simulated amounts of mean annual precipitation do not reach the observed values. It could be argued that the described subdivision of the study area into a western and an eastern section is at least partly an artificial phenomenon caused by two independent observation networks until 1989. However, the area of too high simulated precipitation partly extends far into the western states, crossing the former boundary between East and West Germany. This is especially true for the CLM which clearly overestimates precipitation along the North Sea coastline and points to systematic model errors rather than to inconsistencies in measurement systems.

\subsection{Uncertainty ranges}

For both investigated parameters the bias of annual mean values over Germany has been calculated for every possible combination of a RCM (4 models) with a reference data set (3 references). The resulting uncertainty range for the simulated annual mean $2 \mathrm{~m}$ temperature is $\left[-1.1^{\circ} \mathrm{C} ;+0.9^{\circ} \mathrm{C}\right]$ (Table 1). Additionally, the $95 \%$ percentile of all absolute grid point differences has been computed for mean annual temperature deviations. Depending on the chosen combination of model and reference data set, $95 \%$ of all grid points in Germany show a temperature bias of less than $0.5^{\circ} \mathrm{C}$ to less than $1.8^{\circ} \mathrm{C}$. For precipitation, an uncertainty range of [ $-31 \mathrm{~mm} /$ year; $108 \mathrm{~mm} /$ year] could be derived. The $95 \%$ percentile of relative differences in mean annual precipitation lies between 26 and $59 \%$.

\section{Conclusions}

Results of a multi RCM ensemble for Central Europe have been presented and compared to different reference data sets. In this paper, only $2 \mathrm{~m}$ temperature and total precipitation were considered as these two parameters are the most important atmospheric quantities in hydrological applicatons.
Depending on the RCM which is used for dynamical downscaling of global scale datasets, the same climatic "situation" (in our case the period 1979-1993) is represented differently. However, basic features such as the mean annual cycles of $2 \mathrm{~m}$ temperature and precipitation are simulated similarly by all models and agree with the reference data sets which is a sign of correctness of the representation of basic physical processes in the models. Differences between RCM results may be caused by different parameterisations of certain processes, different numerical techniques, different vertical resolutions and in the present study also by different regional model domains. Due to this multitude of potential factors leading to differences in model results, a detailed interpretation and the attribution of causes of simulation differences is difficult using the current model setup. More detailed and consistent investigations using additional simulations are planned for the near future. For instance, the effect of regional model domain size and the nesting hierarchy will be analysed in more detail.

Comparing the reference data sets with each other it becomes evident that also observational datasets are subject to errors and uncertainties. In many cases, these uncertainties are of the same magnitude as differences between RCM results. The calculated bias of regional climate simulations therefore strongly depends on the specific reference dataset used for model validation. Ideally, several observational data sources should be utilised and biases should be calculated with respect to each single reference data source.

In the present study, no single model could be identified as systematically producing worse or better results than other RCMs which is partly due to differences in the reference data sets used for validation. The derived uncertainty ranges are of great importance for assessing the reliability and robustness of regional climate change scenarios. The analysis of such scenarios is a further step within the QUIRCS project. The presented quality assessment of climate model simulations can serve as a first benchmark regarding uncertainties of input parameters in hydrological schemes. However, for specific applications (i.e. water balance modelling and flood analysis) uncertainties of annual and monthly mean values of climatic input are only of limited value. Information on a higher temporal resolution is needed, for example an assessment of the simulation quality for specific circulation patterns and for strong precipitation events. Based on the described multi-model-ensemble, these topics will now be investigated in more detail. A second focus will be laid on the investigation of the influence of regional model domain size and nesting hierarchy on the simulated climate parameters.

The quality of RCM performance as well as inter-model differences also vary in space (Figs. 4, 5 and 7) and obviously depend on regional and local factors (topography, influence of maritime and continental air masses etc.). Therefore, without a more detailed investigation of the influence of specific regional features on model uncertainty, a regionalisation of our results and their transferability to other regions still remains difficult. 
Regionally, the uncertainty ranges for simulated $2 \mathrm{~m}$ temperature and precipitation presented in this study are expected to have a significant influence on the results of hydrological applications. Biases of up to $2 \mathrm{~K}$ for mean annual $2 \mathrm{~m}$ temperature and of more than $50 \%$ for mean annual precipitation will for instance definitely cause biases in simulated runoff in physically based hydrological schemes. Therefore, it is strongly reommended to account for uncertainties in climatological input parameters e.g. by adopting the ensemble concept which means carrying out multiple simulations using different or disturbed atmospheric forcings. In a medium-term view, the quality of regional climate simulations can be expected to increase as a result of improved process description. Additionally, the further development of non-hydrostatic schemes (explicit description of vertical acceleration of air masses) and increases in computing power will allow finer horizontal resolutions (less than $10 \mathrm{~km}$ ) and therefore a more realistic representation of orographically controlled local meteorological features.

Acknowledgements. The presented work has been carried out within the research project QUIRCS which is funded within the German Climate Research Program (DEKLIM). The authors wish to thank all involved persons for their help and for supply of observational data, model results and figures.

Edited by: P. Krause, K. Bongartz, and W.-A. Flügel

Reviewed by: anonymous referees

\section{References}

Doms, G. and Schättler, U.: A Description of the Nonhydrostatic Regional Model LM, Part I: Dynamics and Numerics, LM_F90 2.18, Deutscher Wetterdienst, Offenbach, Germany, 2002.

Dyck, S. and Peschke, G.: Grundlagen der Hydrologie, Verlag für Bauwesen, Berlin, 536 pp., 1995.
Gibson, J. K., Källberg, P., Uppala, S., Hernandez, A., Nomura, A., and Serrano, E.: Era description, ECMWF Re-Analysis Project Report Series 1, Reading, UK, 1997.

Giorgi, F. and Francisco, R.: Evaluating Uncertainties in the Prediction of Regional Climate Change, Geophys. Res. Lett., 27, 9, 1295-1298 (1999GL011016), 2000.

Grell, G. A., Schade, L., Knoche, R., Pfeiffer, A., and Egger, J.: Nonhydrostatic climate simulations over complex terrain, J. Geophys. Res., 105 (D4), 29 595-29 608, 2000.

Häckel, H.: Meteorologie, 4. Aufl., Ulmer, Stuttgart, 448 pp., 1999.

Jacob, D.: A note to the simulation of the annual and inter-annual variability of the water budget over the Baltic Sea drainage basin, Meteorol. Atmos. Phys., 77, 61-73, 2001.

Jacob, D. and Podzun, R.: Sensitivity studies with the regional climate model REMO, Meteorol. Atmos. Phys., 63, 119-129, 1997.

Kücken, M. and Hauffe, D.: The Nonhydrostatic Limited Area Model LM (Lokal Modell) of DWD with PIK Extensions, Part II: Extensions User Guide, LM_F90 2.16, Potsdam Institut für Klimafolgenforschung, Potsdam, Germany, 2002.

Murphy, J. M., Sexton, D., Barnett, D., Jones, G., Webb, M., Collins, M., and Stainforth, D.: Quantification of modelling uncertainties in a large ensemble of climate change simulations, Nature, 430, 768-772, 2004.

New, M., Lister, D., Hulme, M., and Markin, I.: A high-resolution data set of surface climate over land areas, Clim. Res., 21, 1-25, 2002.

Roeckner, E., Arpe, K., Bengtsson, L., Christoph, M., Claussen, M., Dümenil, L., Esch, M., Giorgetta, M., Schlese, U., and Schulzweida, U.: The atmospheric general circulation model ECHAM-4: Model description and simulation of the present day climate, Max Planck Institute for Meteorology, Report No. 218, 90 pp., 1996.

Semmler, T.: Der Wasser- und Energiehaushalt der arktischen Atmosphäre. PhD thesis, Max Planck Institute for Meteorology, Examensarbeit Nr. 85, 106 pp., 2002.

Wilby, R. L. and Wigley, T. M. L.: Downscaling General Circulation Model output: a review of methods and limitations, Prog. Phys. Geogr., 21, 530-548, 1997. 